\title{
DEVELOPING A CHALLENGES LANDSCAPE RELATING TO DRUG SAFETY, PROVISION, AND DISTRIBUTION IN RESOURCE-LIMITED SETTINGS FOR THE CASE OF HIV/AIDS
}

\author{
B. Huysamen ${ }^{1 *}$, I.H. de Kock ${ }^{1} \&$ L. Bam ${ }^{1}$
}

\section{ARTICLE INFO}

\section{Article details \\ Presented at the $29^{\text {th }}$ annual conference of the Southern African Institute for Industrial Engineering (SAIIE), held from 24-26 October 2018 in Stellenbosch, South Africa \\ Available online \\ 9 Nov 2018}

Contact details

Corresponding author

18200648@sun.ac.za

\section{Author affiliations}

1 Health Systems Engineering and Innovation Hub, Department of Industrial Engineering, Faculty of Engineering, Stellenbosch University, South Africa

DOI

http: / /dx.doi.org/10.7166/29-3-2048

\section{ABSTRACT}

Since 2010, pharmaceutical organisations have begun to provide drug patents in sub-Saharan Africa through the UN Medicine Patent Pool. This initiative allows any pharmaceutical manufacturer to access these patents and manufacture the drugs, thereby aiming to decrease the associated lead times and costs. The participation of numerous manufacturers, some of whom may not have wellestablished quality control systems in the market, intensifies the need for effective drug quality monitoring. Research indicates that it is often the case that these 'niche drug provision systems' face many challenges with the quality of new-generation drugs and the implementation of effective pharmacovigilance $(P V)^{1}$ systems for the reporting of adverse drug reactions. The lack of resource efficiency in adverse drug reaction reporting within the sub-Saharan context is also a growing concern.

\section{OPSOMMING}

Sedert 2010 het farmaseutiese organisasies deur middel van die UN Medicine Patent Pool medisyne patente vrygestel vir lae- en middelinkomste lande. Hierdie inisiatief laat toe dat enige farmaseutiese vervaardiger die patente kan gebruik om medisyne te vervaardig; sodoende word die koste en vervaardigingstyd verminder. Aangesien ' $n$ aantal verskillende vervaardigers, waarvan sommiges nie goed gevestigde kwaliteit stelsels het nie, kan deelneem, moet daar goeie 'pharmacovigilance' (PV) toegepas word. Navorsing dui egter daarop dat dit dikwels die geval is dat hierdie plaaslike medisyne vervaardigers baie uitdagings ervaar in verband met medisyne voorsiening wat weer effektiewe PV-stelsels impliseer. Die gebrek aan menslike hulpbronne vir die monitering van negatiewe reaksies op die medisyne in hierdie lande is ook ' $\mathrm{n}$ groeiende probleem.

In the contemporary landscape it is evident that there has been a significant shift in health care trends around the world that calls for innovative drug manufacturing, distribution, and surveillance monitoring. According to Rohrbach [1], the growing demand for healthcare - combined with the switch in focus from treatment to prevention - has placed pharmaceutical companies under pressure from governments and consumers to reduce their prices and improve the value of their therapies. However, other stakeholders, such as the World Health Organization, also contribute to this pressure. The epidemic of communicable diseases in low- and middle-income countries adds to the pressure that pharmaceutical companies experience from stakeholders to ensure an affordable drug supply. According to the World Health Organization, in 201636.7 million people were living with

1 In this article, 'PV' means 'pharmacovigilance' which refers to the science and application of the detection, assessment, and monitoring of adverse drug reactions after drugs have been licensed for use. 
HIV/AIDS, the majority of whom lived in low-middle income countries [2]. These factors, combined with strict drug patent laws, make the affordable supply of drugs in these countries problematic [3].

Thus in 2010 the UNITAID medicine patent pool (MPP $)^{2}$ was established to improve access to the treatment of HIV, tuberculosis (TB), and hepatitis $C$ by allowing access to specific drug patents [4], [5]. This innovation has played a significant role in addressing the HIV/AIDS epidemic from the perspective of access to medicine, as between 2005 and 2016 the proportion of patients receiving treatment increased from $6.9 \%$ to $53 \%$ globally [2]. However, the MPP has given rise to other challenges [6]. As multiple drug manufactures are allowed to access the drug patents, quality monitoring in these settings has to be very well-established. Such challenges are often attributed to inadequate local drug manufacturing and distribution systems [6].

However, when aiming to address specific challenges brought about by an intervention, as is the case with those arising from the MPP allowing any drug manufacturers access to patents, the context within which such a system exists has also to be considered. As mentioned earlier, the MPP only allows access to patents in low- and middle-income countries, which often have only limited resources. One example of limited resources in the sub-Saharan African region is the deficit of 24.8 million doctors and nurses, resulting in 2.3 healthcare workers per 1000 people in Africa. This is $90 \%$ less than in the United States of America, where there are 24.8 healthcare workers per 1000 people [7]. In addition to the limited human resources in these countries, funding and opportunities for research and development are also limited [8]. Thus, when considering the challenges that arise through the implementation of the MPP, the context of limited resources should also be considered.

These challenges in drug manufacturing and distribution in the context of resource-limited settings call for an effective, well-established drug monitoring and pharmacovigilance (PV) ${ }^{3}$ system to assist in improving patient safety. In order to develop such a PV system that will support, facilitate, and improve additional challenges brought on by inadequate drug manufacturing and distribution, the challenges need to be identified and understood to ensure that such a PV system overcomes them and does not give rise to any additional ones. It is also recognised that the current PV systems do not adequately support the unique MPP practices. This highlights the need for a PV system to support the unique needs of drug monitoring in such a setting, and to provide evidence that warrants the deployment of a PV system to support effective drug monitoring. In order to develop the characteristics of such a 'niche PV system'4, a requirement specification will have to be developed. This requirement specification will be based partly on the insights gained from evaluating the challenges and incorporating best practices, current PV requirements, and the ability of the PV system to function in such a setting. A niche PV system can then be designed either by transforming the traditional PV system or by transitioning to a new PV system using the developed requirement specification.

This paper, however, will focus on the challenges posed by drug manufacturing and distribution systems within resource-limited settings, which will be incorporated into the requirement specification for PV systems for such a setting. These challenges will be identified by conducting a systematic review, after which they will be arranged into a challenges landscape to understand the system perspective. Due to the high prevalence of HIV in South Africa, this research inquiry will consider challenges that arise with the roll-out of antiretrovirals (ARVs) [2].

\section{CONTEXTUALISATION: MPP DRUG SAFETY, MANUFACTURING, AND DISTRIBUTION IN RESOURCE-LIMITED SETTINGS}

Due to the growing number of HIV/AIDS patients without treatment in low- and middle-income countries, it was evident that an innovative way to provide antiretroviral treatment (ART) had to be

2 MPP is an initiative which allows any manufacturer to access the available patents and manufacture drugs; thereby aiming to decreasing lead time and costs associated with these drugs.

3 'Pharmacovigilance' is defined as the science and application of the detection, assessment, and monitoring of adverse drug reactions after drugs have been licensed for use.

4 In this research inquiry, 'niche PV system' refers to a PV system that is designed for a specific population, implying a specific region and a specific drug. Such a PV system will most likely operate and be managed differently from 'traditional' PV systems. 
implemented [2], [3]. One of the reasons that very few HIV/AIDS patients did not receive treatment was the high prices for treatment caused by the patent system, in which a company had the monopoly over a particular drug. ARVs also have to be taken in combination with other drugs, each with their own patent; and this also resulted in very high prices [3].

Thus, in 2010 the MPP was established by UNITAID to increase access to treatments for specific communicable diseases such as HIV, hepatitis C, and TB in low- and middle-income countries through sharing technologies and patents [4]. A patent pool is defined as a collaboration between patent holders and other third parties, where licences are offered for use in exchange for a fixed price or royalties. The implementation of a medicine patent pool makes the production and distribution of drugs accessible to a broader population at a faster rate and at more affordable prices [3]. The WHO assist the MPP by prioritising the medicines that were required, and patent holders voluntarily agreed to license their medicines to the MPP, which in turn issued generic pharmaceutical companies with licence rights to manufacture these medicines.

The implementation of MPP has many advantages, such as facilitating competition, improving lowcost manufacturing, and encouraging research and development (R\&D) [3], [9]-[11]. Through the implementation of the MPP, competition is facilitated because multiple drug manufacturing companies can access the same patents. As competition between manufacturers increases, drug prices drop, making drugs more affordable [9]. Through the MPP, low-cost manufacturing companies are also able to approach the patent pool to negotiate licensing agreements to create generic versions of these drugs [3]. As mentioned earlier, antiretroviral drugs need to be taken in combination with other drugs in order to be effective [3]. However, the patent pool encourages R\&D and innovation for the treatment of HIV/AIDS, as the patents for the drugs are accessible and can be used for new fixed-dosage combinations [3], [10]. The manufacturing companies are given the flexibility to develop new and appropriate formulations and fixed-dosage combinations to meet the specific needs of patients. Often the drugs are not adapted for use in developing countries - as in the case of paediatric treatments, as virtually no children are affected by HIV/AIDS in developed countries [9]-[11].

However, certain challenges arise when considering the provision of access to medicine through the MPP, such as local manufacturing, distribution, R\&D, sub-standard medicines, and other regulatory issues [6]. The patents are available to any drug manufacturing companies in low- and middleincome countries that wish to make use of them; and although the manufacturers need to meet certain quality standards, it is often difficult to monitor the quality process of these drugs. Research found that, although the MPP does not directly cause any difficulties, the drug manufacturing and distribution system in these settings, made possible through the MPP, produces numerous challenges [12], [8].

In section 3, the different challenges that arise due to inadequate manufacturing and distribution systems in resource-limited settings will be identified through a systematic review, after which they will be discussed before developing a challenges landscape.

\section{CHALLENGES POSED BY DRUG MANUFACTURING, DELIVERY, AND RESOURCE-LIMITED SETTINGS}

As previously mentioned, the challenges that arise in the manufacturing and distribution of drugs for which patents are made available through the MPP can be attributed to inadequate drug manufacturing and distribution systems [6], [12]. These challenges affect patient safety, and so need to be addressed to ensure that the necessary monitoring systems are in place. The low- and middle-income countries that access the MPP also often have limited resources, which further complicates the challenges [7].

In this section, the aim is to identify the challenges arising from drug manufacturing and distribution systems in resource-limited settings in developing countries. Once these challenges have been identified through a systematic review, a challenges landscape can be developed to indicate the system perspective, which will contribute to the development of the requirement specification for a PV system in these settings. 
First the approach to, and the results of, the systematic review will be given, after which the different challenges will be defined.

\subsection{Approach}

Due to the great extent of the available literature on drug manufacturing and distribution, a systematic review was conducted to limit the review and ensure that a significant amount of research into the challenges in this landscape could be included. The academic database Scopusthe largest abstract and citation database of peer-reviewed literature ${ }^{5}$ - was used to conduct the primary search protocol. In addition, since the use of keywords in a search protocol is most effective in Scopus, and other databases often deliver irrelevant documents when using this search technique, Scopus was deemed a suitable platform for this research inquiry. However, given the focus on healthcare environments, databases such as PubMed were used for informal search methods, and serendipitous findings were included in the research. Using Scopus, a total of 1870 relevant articles were found using specific key words and phrases (Table 1). In order to find the most relevant documents, a set of different criteria points were included in the search protocol. These criteria points included only documents from 2010 and onwards, as the MPP was only introduced in 2010. Furthermore, documents that were not originally published in English but had been translated, and any duplicate documents, were excluded. The remaining documents' titles and abstracts were then screened for relevance. Documents concerned with relevant topics, such as the challenges posed by drug manufacturing or distribution systems or settings with limited resources regarding HIV/AIDS, were included in the final set. In the end, a total of 41 relevant documents were found from Scopus and seven from PubMed. These were reviewed and used to identify the challenges that are experienced in the context of drug manufacturing and distribution systems in resource-limited settings.

The process that was followed to limit the number of documents can be found in Figure 1.

Table 1: List of search terms used in systematic review

\begin{tabular}{|c|c|c|c|}
\hline Index & Search terms & $\begin{array}{c}\text { Number of } \\
\text { articles }\end{array}$ & $\begin{array}{c}\text { Number after } \\
2010\end{array}$ \\
\hline 1 & Drug Manufacturing & 480 & 257 \\
\hline 2 & Drug Manufacturing \& Challenges & 45 & 31 \\
\hline 3 & Drug Manufacturing \& HIV & 4 & 1 \\
\hline 4 & Drug Manufacturing \& Developing Countries & 16 & 1 \\
\hline 5 & Drug Manufacturing \& HIV \& Challenges & 1 & 1 \\
\hline 6 & Drug Manufacturing \& Challenges \& Developing Countries & 3 & 102 \\
\hline 7 & Drug Manufacturing \& Quality & 188 & 147 \\
\hline 9 & Drug Distributions \& Challenges \& HIV & 232 & 7 \\
\hline 10 & Drug Distributions \& Challenges \& Developing Countries & 14 & 84 \\
\hline 11 & Drug Resistance \& HIV \& Developing Countries & 352 & 257 \\
\hline 12 & Counterfeit drugs \& Developing Countries & 126 & 123 \\
\hline 13 & Resource Limited Settings \& Challenges \& HIV & 337 & 17 \\
\hline 14 & Resource Limited Settings \& Challenges \& developing & 144 & 5 \\
\hline 15 & Countries & 24 & 8 \\
\hline 16 & Patient safety \& HIV \& Developing Countries & 10 & 9 \\
\hline 17 & Drug Packaging \& Challenges \& Developing Countries & 58 & 29 \\
\hline 18 & Adverse Drug Reactions \& Drug Manufacturing & 84 & \\
\hline 19 & Adverse Drug Reactions \& HIV \& Developing countries & & \\
\hline
\end{tabular}

5 https://www.elsevier.com/solutions/scopus 


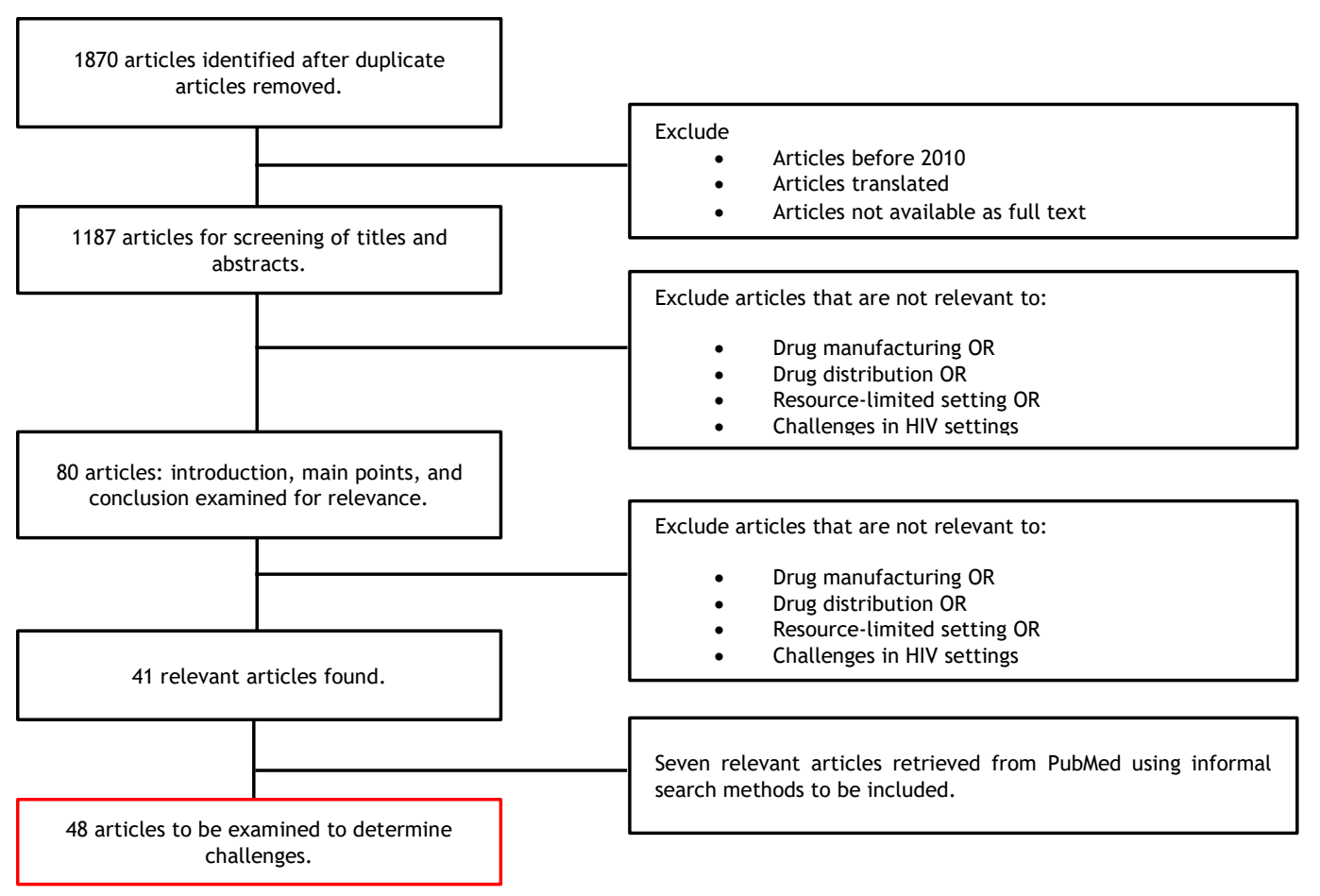

Figure 1: Process of systematic review

\subsection{Results}

Once the systematic review had been completed, the different challenges posed by inadequate drug manufacturing and distribution systems, and the challenges posed by limited resources, could be identified and listed. From the literature the following 19 factors were identified:

- Drug dosages

- Labelling \& packaging

- Specialised drugs

- Traditional medicines

- Paediatric drugs

- Drug resistance

- Drug quality

- Counterfeit drugs

- Substandard drugs

- Record-keeping
- $\quad$ Adverse drug reactions (ADR)

- Drug-drug interactions

- Drug adherence

- Drug supply

- Drug shortages

- Drug stock-outs

- Late ART initiation

- Lack of safety reporting

- Integrity of system

Table 2: Overview of occurrences in systematic review

\begin{tabular}{|c|c|c|c|c|c|c|c|c|c|c|c|c|c|c|c|c|c|c|c|}
\hline \multicolumn{20}{|c|}{ Occurrences of challenges in systematic review } \\
\hline \multirow{2}{*}{ Date } & \multicolumn{5}{|c|}{ Drug Manufacturing } & \multicolumn{3}{|c|}{$\begin{array}{l}\text { Combination of } \\
\text { distribution and RLS }\end{array}$} & \multicolumn{7}{|c|}{ Combination of manufacturing, distribution and RLS } & \multicolumn{4}{|c|}{ RLS } \\
\hline & Dosages & $\begin{array}{c}\text { Paediatric } \\
\text { drugs }\end{array}$ & $\begin{array}{c}\text { Specialised } \\
\text { drugs }\end{array}$ & $\begin{array}{c}\text { Traditional } \\
\text { medicine }\end{array}$ & Labelling & \begin{tabular}{|c} 
Drug \\
supply
\end{tabular} & $\begin{array}{l}\text { Drug } \\
\text { stock- } \\
\text { outs }\end{array}$ & $\begin{array}{c}\text { Drug } \\
\text { shortages }\end{array}$ & $A D R$ & $\begin{array}{c}\text { Drug } \\
\text { adherence }\end{array}$ & Quality & $\begin{array}{c}\text { Counterfeit } \\
\text { drugs }\end{array}$ & $\begin{array}{l}\text { Drug-drug } \\
\text { interactions }\end{array}$ & $\begin{array}{c}\text { Substandard } \\
\text { drugs }\end{array}$ & $\begin{array}{l}\text { Drug } \\
\text { resistance }\end{array}$ & $\begin{array}{l}\text { Lack of } \\
\text { safety } \\
\text { reporting }\end{array}$ & $\begin{array}{l}\text { Record- } \\
\text { keeping }\end{array}$ & $\begin{array}{l}\text { Late ART } \\
\text { Initiation }\end{array}$ & $\begin{array}{l}\text { Integrity } \\
\text { of system }\end{array}$ \\
\hline 2010 & & & & $x x$ & & & $x$ & & & $x$ & $x x$ & & & $x$ & & $x x$ & $x x$ & $x$ & $x$ \\
\hline 2011 & $x$ & $x$ & $x$ & & & $x x$ & $x$ & $x$ & $x x$ & $x x$ & $x$ & & & & $x$ & $x$ & & $x x$ & \\
\hline 2012 & & & & & & & & & $x x$ & $x$ & & $x$ & & & & & & & \\
\hline 2013 & $x$ & & & & $x$ & $x$ & $x$ & & $x$ & $x$ & $x$ & $x$ & $x x$ & $x$ & $x x$ & & & & \\
\hline 2014 & & & & & & $x$ & & & $x \times x$ & $x x x$ & $x$ & $x$ & & $x$ & & $x$ & $x$ & $x$ & $x$ \\
\hline 2015 & & & $x$ & & & & & & $\mathrm{x}$ & $x$ & $x$ & & $x$ & $x$ & & & & & \\
\hline 2016 & $x$ & $x$ & $x$ & & & & & $x$ & $x \times x x$ & & $x$ & & $x$ & & & $x$ & $x$ & & \\
\hline 2017 & & $x$ & & $\mathrm{x}$ & $x$ & & & & & & $x$ & $x$ & & & & & $x$ & & \\
\hline Total & 3 & 3 & 3 & 3 & 2 & 4 & 3 & 2 & 13 & 9 & 8 & 4 & 4 & 4 & 3 & 5 & 5 & 4 & 2 \\
\hline
\end{tabular}

Each $\mathrm{X}$ represents a document

From the data provided in Table 2, a number of trends seem to emerge, as some challenges are only mentioned in more recent years. For example, labelling, specialised drugs, drug-to-drug interactions, and lack of reporting have appeared in the more recent literature, while challenges 
such as drug shortages and drug resistance have not appeared in the literature in recent years. From Table 2 it can also be seen that certain challenges have occurred more constantly over the last eight years, such as ADR and quality challenges.

\subsection{Defining challenges}

The 19 factors that were identified in the systematic review have a specific impact on the pharmaceutical and healthcare systems. These challenges are defined and explained in the next sub-section.

\subsubsection{Adverse drug reactions}

According to the WHO, an ADR is defined as "any response to a drug which is noxious and unintended, and which occurs at doses normally used in man for prophylaxis, diagnosis, or therapy of disease, or for the modification of physiological function" [13]. ADRs can affect the treatment process and have negative effects on patients' quality of life, especially for HIV-infected patients on ART. Serious ADR often causes patients to stop taking drugs, leading to a lack of drug adherence or to treatment failure, which negatively impacts patients and society. ADRs are also often a cause of re-admission to a hospital, aggravating the health care burden in resource-limited settings [14]-[19]. It has also been shown that ADRs have been found to be preventable, justifying the need to improve pharmacovigilance. The early detection of ADRs is also pivotal when ensuring the sustainability and optimisation of a treatment process. However, it has been reported that detection, especially in paediatric treatments, is difficult [20]. Furthermore, through the MPP, multiple drug manufacturers are able to produce generic drugs and new fixed-dosage combinations, making it critical that ADRs in HIV patients are monitored carefully [14], [18], [19].

\subsubsection{Drug adherence}

'Drug adherence' refers to patients keeping to the recommendations made for the dosage, timing, and frequency of taking their medication. With regard to ART, it is said that $95 \%$ drug adherence is required to ensure that patients do not develop resistance or suffer from treatment failure [21]. From the literature consulted, it has been determined that non-adherence in ART is caused by a range of different factors; but one of the main causes is ADR [17], [18], [22]. However, studies in developing countries have also indicated that other factors contribute to non-adherence, such as dissatisfaction with the healthcare system, perceived stigmas, distance to ART clinics, limited social support, poor record-keeping, the attitude of healthcare workers, and certain personal factors [23], [17], [21]. Studies do indicate, however, that adherence can be improved with peer counselling and education [24].

\subsubsection{Quality}

Ensuring that the drugs that patients take are safe and effective is one of the priorities of the pharmaceutical industry, and it needs to be continuously addressed throughout the process. Many different aspects, such as good manufacturing practices, quality monitoring, and drug plant characteristics contribute to low-quality drugs. It has been found that, in low income countries, the quality of drugs is often inconsistent; thus proper quality control should be assessed more often, especially when new drug manufacturers are used [25]-[27]. Another aspect to consider when addressing drug quality is the production of generic drugs, which is promoted through the MPP. Generic drug manufacturing and the production of fixed-dosage combinations challenge the existing system, as the different areas of responsibility are misunderstood [28], [23].

\subsubsection{Lack of reporting}

Limited human resources in developing countries contribute to the lack of reporting of ADRs, especially in public HIV healthcare systems. Most low- and middle-income countries have inadequate legislation for mandatory reporting by health care professionals [29], [30], [31]. Furthermore, it has been found that the severity and preventability of ADRs are often under-reported in developing countries, possibly due to inadequate healthcare resources and knowledge among healthcare workers in these regions [14].

\subsubsection{Record-keeping}

Medical health records are essential to health care providers, as they contain specific information about a patient, such as their unique patient identifiers and medical history. Medical health records contain vital information about a patient's health, and are needed for their current and future treatment. Health care providers are required to write up health records so that the information is available when the patient returns to a health care facility [32], [33]. However, it is often the case 
in developing countries that effective record-keeping is a challenge [31], [34]. Healthcare providers mention that patients' records are often lost, resulting in the loss of all previous data, and sometimes even leading to certain medical procedures being repeated [21]. This therefore underpins the need for effective record-keeping systems, such as electronic health records.

\subsubsection{Counterfeit drugs}

The WHO describes counterfeit or falsified drugs as "medical products that deliberately/ fraudulently misrepresent their identity, composition or source" [35]. The WHO also states that counterfeit drugs can be branded or generic drugs that contain the incorrect ingredients, or none at all, or inadequate amounts of active ingredients, or that are falsely packaged [36]. The health of patients who receive counterfeit drugs is threatened, as they are at risk of developing ADR or drug resistance [23], [27], [28], [37]. Counterfeit drugs are often a concern in areas where there is a shortage of drugs, or drug manufacturing and distribution systems are not registered [23], [38].

\subsubsection{Drug-drug Interactions}

The interaction between ARVs and other drugs is often harmful to a patient's treatment procedure. ARVs are often co-administered with antitubercular medication; however, this often leads to a higher frequency of drug-induced liver incidents and peripheral neuropathy. Thus TB/HIV coinfected patients' treatment should be managed more carefully. 'Drug-drug interaction' is defined as a change in the effect of the drug when it is taken together with another drug, and it can often lead to ADR [39]. The use of traditional medicines has also given rise to challenges in drug-drug interactions [23].

\subsubsection{Drug supply}

In developing countries, drug supply has often been a concern, especially for illnesses such as TB and HIV/AIDS, whose treatment requires a strict regime to be effective. Furthermore, when limited amounts of ART are available, ethical issues often arise about how the medication should be prioritised for different patients [23]. Delays in drug delivery in resource-limited settings are often caused by poor infrastructure such as poor roads and by financial burdens such as a lack of funding for fuel [37], [40]. The challenges posed by poor drug supply involve all aspects of the supply chain, from ordering systems to the storage and distribution of drugs. Case studies on weak ARV supplies in South Africa found that they were often caused by poor communication between provincial districts and facilities or between the consumer and the facilities. Studies have shown that supply systems that rely on consumer ordering affect shortages [41].

\subsubsection{Late ART initiation}

From the literature it has become evident that the need to ensure that people start their treatment during the early phases of the disease is just as important as ensuring that patients receive treatment [42]. Although there is no clear definition of just when it is 'late' for a patient to start ART, it can be deduced that it is when a patient's CD4 count is very low (CD4 $<50$ cells $/ \mu \mathrm{L}$ ). Patients who initiate late ART have a higher risk of opportunistic infections than patients who start treatment at a higher CD4 count, with TB being the most common illness [43], [44]. From previous studies, the causes of late ART initiation can be grouped into health system-related issues, socio-economic obstacles, or inappropriate treatment criteria [44].

\subsubsection{Substandard drugs}

The WHO defines substandard drugs as "authorized medical products that fail to meet either their quality standards or specifications, or both" [35]. A drug is thus regarded as a substandard drug if it contains too many or too few active ingredients in comparison with the formulation specifications. However, there have been substandard drugs that were toxic in nature or that contained fatal levels of toxic ingredients. Substandard drugs are often found in poorer settings with manufacturing and distribution systems that use unqualified personnel and inadequate control systems. Substandard drugs are more frequently found, and pose a greater threat to patients than counterfeit drugs [27], [36].

\subsubsection{Dosages}

Taking the correct dosage when on ART is important, since taking an incorrect dosage leads to there being an inadequate amount of the drugs to fight the virus. Often, when tablets are split, asymmetry results in an unproportioned dosage of the ARV drugs. Furthermore, it cannot be assumed that the ingredients are evenly distributed in a tablet; thus pill splitting is not recommended [45]. 


\subsubsection{Drug resistance}

Drug resistance is when the response to a drug in a susceptible parasite population decreases significantly [46]. According to studies by the WHO, it was found that in 2010 the prevalence of HIV drug resistance for patients starting treatment was $6.8 \%$ for any drug, and that the treatment of these patients was more likely to fail [47], [48]. Drug resistance leads to further challenges relating not only to the patient's own future treatment, but also to the whole community [25].

\subsubsection{Drug stock-outs}

The WHO defines a drug stock-out as the total absence of a medication that has been identified as essential at the point of service delivery [49]. Drug stock-outs are often the result of poor infrastructure and insufficient human resources [40], [50]. Although alternative ARTs are often provided in the case of a stock-out, it still poses the threat of drug resistance, as it might cause suboptimal drug levels [34]. It has been reported that one-third of countries worldwide struggle with drug stock-outs, thus increasing the risk of treatment failure and failed drug adherence [30], [34], [51]. To ensure that stock-outs do not occur, it is critical that ART programme planning and rational forecasting processes are in place [30].

\subsubsection{Paediatric drugs}

The need for paediatric antiretroviral drugs is much higher in low- to middle-income countries, as developed countries have significantly reduced the mother-to-infant HIV rate. Furthermore, the use of adult ART for children is seen as ineffective, as children absorb and metabolise drugs differently than do adults. Through the MPP, drug manufacturers in developing countries can develop innovative fixed-dosage combinations specifically for paediatric use. However, when developing paediatric drugs, the palatability, taste, size, dosages, formulation, and ease of handling or administration of the drugs should be considered [45], [52].

\subsubsection{Specialised drugs}

In developing countries, certain specialised drugs are manufactured to specific contextual criteria. Two examples of such drugs that occur in the HIV treatment context are paediatric antiretrovirals and the use of traditional medicines. This is often the case in countries that are part of the MPP, as the patents often only cater for a developed country's needs [53], [45].

\subsubsection{Traditional medicines}

Many cultural and social differences that further complicate HIV/AIDS treatment in developing countries need to be considered, one being the increasing production and use of traditional medicines [54]. The increased production of these medicines raises issues of quality control, although intercultural standards are being developed for traditional medicines. Aspects to consider in relation to quality control are the use of raw materials, the knowledge of the manufacturers, and the lack of general safety studies [55]-[57].

\subsubsection{Drug shortages}

A drug shortage is defined by the WHO as the insufficient supply of medication or health products to meet the public's and patients' needs [49]. The drugs that are often affected by shortages are produced by smaller generic companies with little redundant capacity, which complicates the situation with production problems [58]. Previous case studies showed that patients who were on a waiting list for ART often died due to drug shortages. However, drug shortages can be prevented if there are sufficient resources to inspect and approve new drugs and ensure the quality of drugs. It has also been predicted that reducing the number of reviews and speeding up inspections would help to avoid shortages [59].

\subsubsection{Integrity of system}

The support, integrity, and confidentiality of health care workers has been seen to have an impact on ART. From the literature it has been found that HIV patients' distrust of and dissatisfaction with the healthcare system can lead to serious problems such as late treatment initiation or poor drug adherence, which often result in drug resistance or treatment failure. Healthcare workers who are supportive will motivate patients to take their ARVs, and educate them about the consequences and benefits of keeping to the treatment programme [21], [44],[60]. A case study [44] revealed that HIV patients often do not seek treatment, as they know that the healthcare staff often discuss their status - which is a very sensitive topic - in public. The compassion and support of healthcare workers are important in ensuring that patients follow through with their treatment [25]. 


\subsubsection{Labelling}

Mislabelling drugs can have a severe impact on a patient's safety, and can be more harmful for them. According to the WHO, labelling on drugs needs to contain the names and amount of the active ingredients, the batch number from the manufacturer, the expiry date, the name and address of the manufacturer, any storage instructions, and directions for use. It is particularly important that the directions and guidelines for use are clearly indicated [61].

\section{CHALLENGES LANDSCAPE}

As previously mentioned, the challenges that were identified in section 3 were found to relate to one another and to have an impact on one another. It was also established that challenges could have (possibly different) impacts on the various parts of the pharmaceutical value chain. Thus, an overview of the 'challenges landscape' is developed here to gain a holistic view of the challenges that face the drug manufacturing and distribution systems in relation to the provision of drug patents through the MPP. The challenges landscape will serve as a guide to determining any shortcomings in the traditional PV system by developing a requirement specification for a (niche) PV system that will support effective and efficient drug surveillance and monitoring. However, the development of the requirement specification falls outside of the scope of this paper; the key focus of this paper is, as mentioned earlier, to develop a challenges landscape to understand the system perspective in these settings.

The pharmaceutical value chain framework used for the purpose of this study has four sections: supply, distribution, product, and health system [62]. The 'supply' section is then sub-divided into 'drug development' and 'manufacturing', while the 'health system' section is split into 'patient usage' and 'monitoring systems' [62].

The challenges landscape, as discussed in the sections that follow, is discussed from three perspectives: firstly, the relationships between the various challenges are considered and presented in a relationship diagram; secondly, the relationship diagram, the pharmaceutical value chain framework, and the various challenges are amalgamated and presented in a schematic representation of the challenges landscape; and thirdly, the linkages and groupings presented in the schematic representation of the challenges landscape are elaborated on.

\subsection{Relationship diagram \& schematic representation of the challenges landscape}

In Figure 2 the respective relationships between the challenges are indicated. These relationships were not necessarily explicitly mentioned in the literature, but after synthesising the information gathered through the systematic literature review, certain correlations and relationships between the different challenges could be identified. The relationships indicated in Figure 2 are grouped so as to indicate the impact a relationship has on a specific section of the pharmaceutical value chain. These sections of the value chain are distinguished in the key provided in Figure 2 . In the case where a relationship has an impact on more than one section, both are indicated. The relationship diagram was used as an aid to create the challenges landscape. Schematic representation of the challenges landscape

Using the relationship diagram in section 4.1 and the information from section 3 , a challenges landscape (Figure 3) was developed to indicate the inter-relationships and impacts between the different challenges, and their relationships with the different stages of the pharmaceutical value chain.

As seen in the schematic representation, the pharmaceutical chain is subdivided into four sections: supply, distribution, product, and health system. The challenges are in three main groups, referred to as A1-A3. They are formed when considering the systematic review and the causes of the challenges - namely, drug manufacturing and distribution in resource-limited settings. A1 refers to challenges due to inadequate manufacturing and distribution systems; $A 2$ to challenges due to quality issues in drug manufacturing and distribution; and $\mathrm{A} 3$ to challenges due to limited resources. These challenges are grouped in subsections within these main groups; these sub-groupings, C1-C8, are discussed in section 4.2 . 


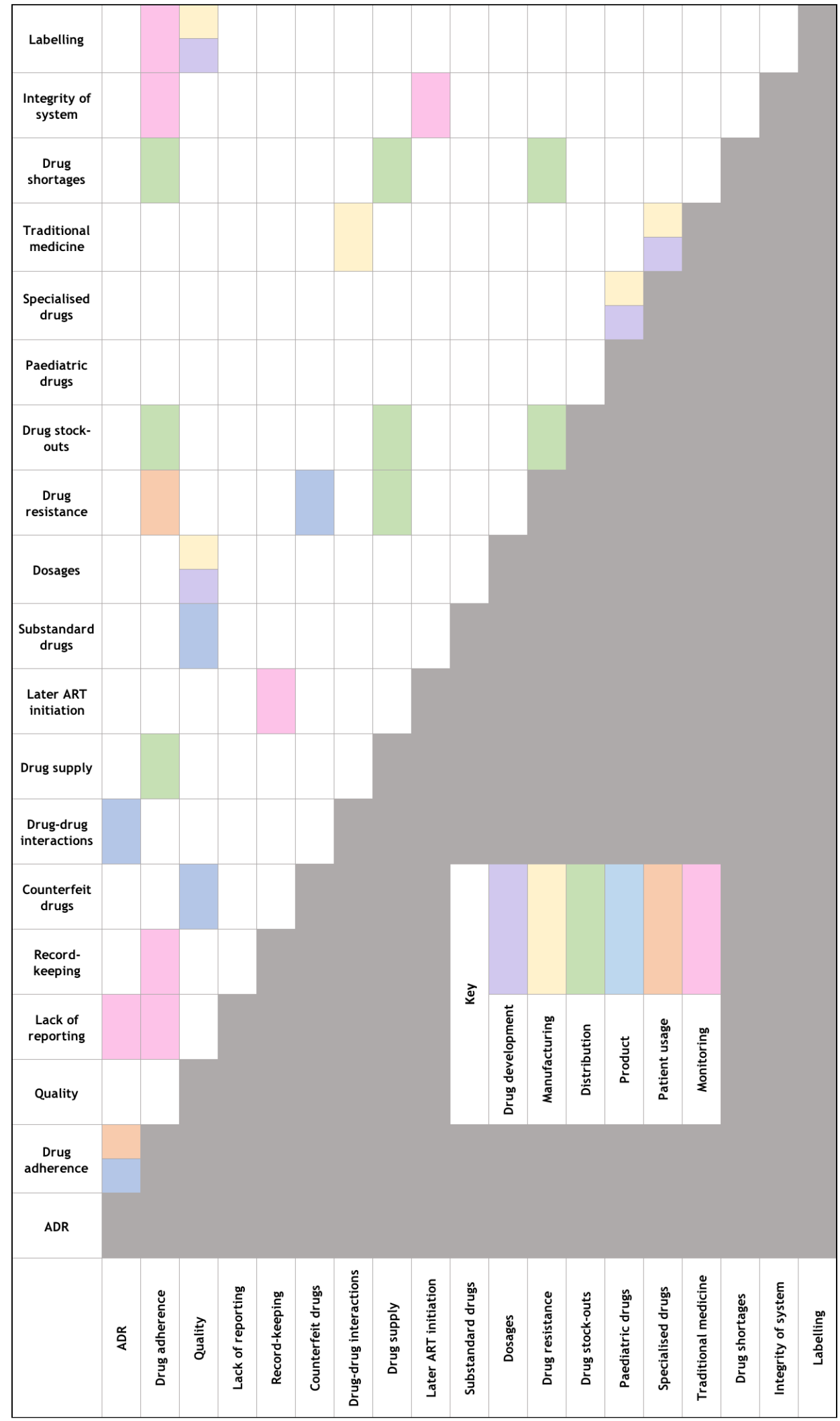

Figure 2: Relationship diagram (see online version for colour) 


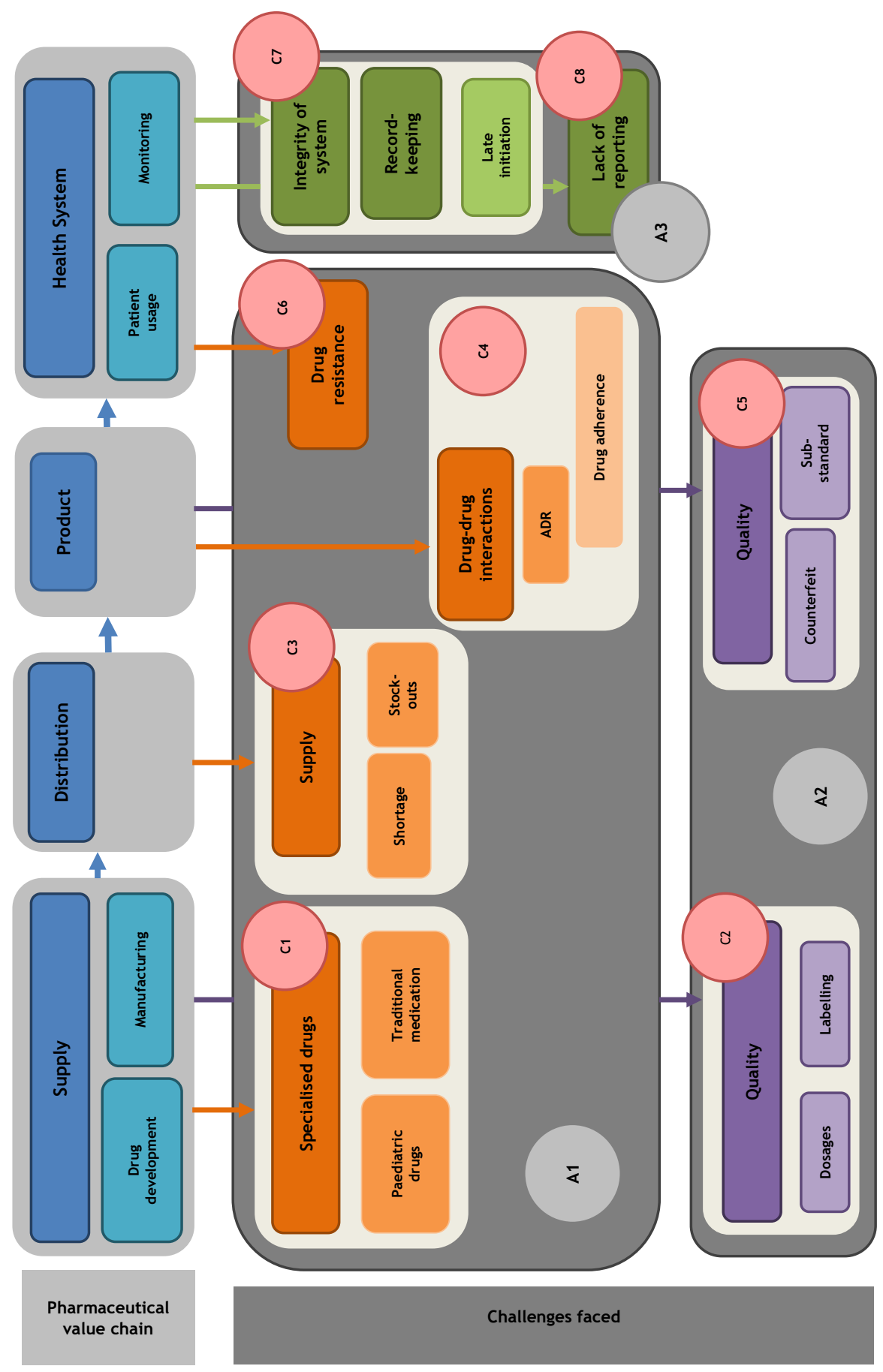

Figure 3: Challenges landscape (see online version for colour)

\subsection{Links and groupings}

As mentioned earlier, the different challenges have certain correlations, impacts, and/or relationships on or with each other, either directly or indirectly, which are illustrated by the challenges landscape in section 4.1. The explanation of the different groupings and relationships in the challenges landscape is provided in Table 3. It should be noted that the groupings and links between the different challenges were created with reference to the literature that was found through the systematic review and provided in section 3. 
Table 3: Explanation of groupings of different challenges

\begin{tabular}{|c|c|c|c|}
\hline Code & Value Chain & Grouping & Explanation \\
\hline C1 & $\begin{array}{l}\text { Drug } \\
\text { development } \\
\text { and } \\
\text { manufacturing }\end{array}$ & $\begin{array}{l}\text { Specialised drugs, } \\
\text { paediatric drugs, } \\
\text { traditional } \\
\text { medicines }\end{array}$ & $\begin{array}{l}\text { In low- and middle-income countries, the development and manufacturing } \\
\text { of drugs often requires the creation of drugs for specific needs of patients, } \\
\text { referred to as 'specialised' drugs. In the case of HIV, the two specialised } \\
\text { drugs that are most often found are paediatric drugs and traditional } \\
\text { medicines [53], [45]. These challenges mostly appear in the phases of drug } \\
\text { development and manufacturing. Furthermore, it is seen that traditional } \\
\text { medicines often have an impact on drug-drug interactions [23]. }\end{array}$ \\
\hline $\mathrm{C} 2$ & $\begin{array}{l}\text { Drug } \\
\text { development } \\
\text { and } \\
\text { manufacturing }\end{array}$ & $\begin{array}{l}\text { Quality, dosages, } \\
\text { labelling }\end{array}$ & $\begin{array}{l}\text { The identified quality challenges have been shown to have an impact on } \\
\text { the supply side of the value chain. Drug manufacturing companies have to } \\
\text { have quality systems in place to ensure that the drugs they manufacture } \\
\text { are safe and effective, and will not harm patients [26], [27]. Inadequate } \\
\text { quality systems in drug manufacturing companies further complicate } \\
\text { challenges such as drug dosage and labelling. If drug manufacturing } \\
\text { companies do not have quality systems in place, the drugs dosages are } \\
\text { often not adequate, as the ingredients are not distributed evenly [45]. The } \\
\text { labels are often also incorrect. These challenges cause further problems } \\
\text { with patient safety [61]. }\end{array}$ \\
\hline $\mathrm{C} 3$ & Distribution & $\begin{array}{l}\text { Drug supply, drug } \\
\text { shortages, drug } \\
\text { stock-outs }\end{array}$ & $\begin{array}{l}\text { In the drug distribution part of the value chain, drug supply in low- and } \\
\text { middle-income countries is one of the major concerns that is further } \\
\text { affected by limited resources in these settings. As mentioned, many } \\
\text { factors affect drug supply, from poor infrastructure to factors in the supply } \\
\text { chain such as ordering systems [41]. The problems in drug supply create } \\
\text { difficulties such as drug shortages and drug stock-outs. These lead to } \\
\text { problems with patient safety, since shortages and stock-outs often are the } \\
\text { causes of drug resistance in patients and poor adherence [34]. }\end{array}$ \\
\hline $\mathrm{C} 4$ & $\begin{array}{c}\text { Product, } \\
\text { patient usage }\end{array}$ & $\begin{array}{c}\text { Drug-drug } \\
\text { interactions, ADR, } \\
\text { drug adherence }\end{array}$ & $\begin{array}{l}\text { Of the challenges that were identified, drug-drug interaction is one that } \\
\text { arises in the final product stage of the value chain. As mentioned, ARVs } \\
\text { often have to be taken in combination with other drugs, which can lead to } \\
\text { negative drug-drug interactions. It has also been found that traditional } \\
\text { medicines, which are often used in low- and middle-income countries, } \\
\text { have an effect on drug-drug interactions [23]. Drug-drug interactions often } \\
\text { also cause serious side effects and ADRs [39]. As previously mentioned, } \\
\text { ADRs often have an effect on a patient's treatment process, as serious } \\
\text { ADRs can impact a patient's adherence to the treatment, since they often } \\
\text { stop taking their medications due to ADRs [21]. This inevitably affects not } \\
\text { just the patient but the community as a whole. Drug adherence implicates } \\
\text { the value chain in both the final product stage and the patient usage } \\
\text { stage. }\end{array}$ \\
\hline C5 & Product & $\begin{array}{l}\text { Quality, } \\
\text { counterfeit drugs, } \\
\text { sub-standard } \\
\text { drugs }\end{array}$ & $\begin{array}{l}\text { The quality of the final product is reduced by ineffective manufacturing } \\
\text { and distributions systems [27], [28]. Drugs of inauspicious quality often } \\
\text { lead to counterfeit drugs or sub-standard drugs. These challenges are } \\
\text { mostly caused by a lack of quality in the drug supply process, and can } \\
\text { seriously affects patient safety. Furthermore, counterfeit drugs often lead } \\
\text { to serious ADR or drug resistance [23], [27], [28], [37]. }\end{array}$ \\
\hline $\mathrm{C} 6$ & Patient usage & Drug resistance & $\begin{array}{l}\text { Drug resistance is one of the challenges in the HIV setting that is } \\
\text { associated with patient usage. Although drug resistance is not grouped } \\
\text { together with other challenges, many factors impact on and lead to drug } \\
\text { resistance. From the identified challenges, the biggest contributors to drug } \\
\text { resistance are drug delivery, shortages, stock-outs, and poor drug } \\
\text { adherence [34], [42]. Furthermore, drug resistance is complicated by } \\
\text { inadequate drug monitoring systems, such as the low integrity of a health } \\
\text { system and poor record-keeping [21], [44]. }\end{array}$ \\
\hline $\mathrm{C7}$ & Monitoring & $\begin{array}{l}\text { Integrity of the } \\
\text { health system, } \\
\text { record-keeping } \\
\text { system, late ART } \\
\text { initiation }\end{array}$ & $\begin{array}{l}\text { In monitoring - the final stage of the drug value chain - many challenges } \\
\text { arise from limited resources. The poor integrity of the health care system } \\
\text { and the lack of effective record-keeping are two of the contributing } \\
\text { factors for late ART initiation. Late ART initiation can be very detrimental } \\
\text { to patient care, and often leads to unnecessary deaths. Furthermore, the } \\
\text { lack of effective record-keeping and dissatisfaction with the health care } \\
\text { system affects drug adherence, which again leads to drug resistance [44]. }\end{array}$ \\
\hline C8 & Monitoring & Lack of reporting & $\begin{array}{l}\text { The lack of reporting during ART is one of the major challenges in } \\
\text { resource-limited settings during the monitoring stage of the value chain. As } \\
\text { mentioned, preventable ADRs have often been found to be under-reported, } \\
\text { leading to further complications such as poor drug adherence and drug } \\
\text { resistance [14]. }\end{array}$ \\
\hline
\end{tabular}

\subsection{The need to investigate the development of a niche PV system}

Given the challenges landscape discussed above, the three perspectives - the relationships between the various challenges, the schematic representation of the challenges landscape, and the discussion on the linkages and groupings - lead to a comprehensive understanding of and insight into the challenges that arise from drug manufacturing and distribution systems that are related to the MPP 
in settings with limited resources. From this challenges landscape, it is evident that there are shortcomings in the current (traditional) PV systems, as the challenges faced in these settings are not considered or incorporated when developing and designing the requirements and characteristics of a traditional PV system [63].

Thus, the challenges landscape highlights the need for an innovative PV system, such as a niche PV system, not only to support, facilitate, and improve the manufacturing and distribution of drugs and to address the challenges faced in these settings, but also to ensure that such a PV system will not create any additional problems or reinforce existing ones. The insights gained from the challenges landscape will assist with the development of a requirement specification for such a niche PV system that will address the current shortcomings in drug surveillance and monitoring in these settings.

\section{CONCLUSION AND FURTHER RESEARCH}

The challenges that arise in the manufacturing and distribution systems of drugs whose patents are made available through the MPP were discussed in this article. The challenges specifically related to developing countries, and challenges faced within the HIV/AIDS setting, were considered. It was determined that these challenges complicate different stages of the pharmaceutical value chain, and thus an innovative PV system is required to address these challenges.

The challenges landscape developed in this paper is a useful tool that indicates the relationships from a system perspective. Furthermore, the challenges landscape and the insights gained from it can be used in combination with other elements that relate to drug surveillance monitoring, such as best practices and current PV characteristics, to develop a requirement specification for an effective PV system in these settings.

In conclusion, this paper highlights the need for an innovative PV system, such as a niche PV system for a specific region and specific drug, to address and possibly eliminate the challenges that are faced in these settings, and to increase the effectiveness and efficiencies of such systems, given their unique characteristics. The insights gained from this paper will be considered when designing a niche PV system by transforming or transitioning from the traditional PV system.

\section{REFERENCES}

[1] Rohrbach, M.. 2017. The decline of the traditional pharmaceutical business model - Expert blog. [Online]. Available: https://blog.kpmg.ch/decline-traditional-pharmaceutical-business-model/. [Accessed: 16-Apr2018].

[2] Sidibé, M. 2017. Global HIV and AIDS statistics. AVERT. [Online]. Available: https://www.avert.org/globalhiv-and-aids-statistics. [Accessed: 16-Apr-2018].

[3] Modell, N. 2003. Swallow the pill and jump in the patent pool - A study into how an HIV/AIDS patent pool would result in cheaper drugs and increase. Intellectual property Dissertation. University of Kent.

[4] Medicines Patent Pool. n.d. Who we are - MPP [Online]. Available: https://medicinespatentpool.org/. [Accessed: 21-May-2018].

[5] Medicine Patent Pool. n.d. What we do - MPP. [Online]. Available: https: //medicinespatentpool.org/what-we-do/. [Accessed: 21-May-2018].

[6] Burrone, E. Global cooperation for IP and development - presentation. [Online]. Availiable: https://slideplayer.com/slide/10673957/. [Accessed: 17-Apr-2018].

[7] Naicker, S., Plange-Rhule, J., Tutt, R.C. and Eastwood, J.B. 2009. Shortage of healthcare workers in developing countries - Africa. Ethn Dis, vol. 19, pp. 160 - 164.

[8] T'Hoen, E., Berger, J., Calmy, A. and Moon, S. 2011. Driving a decade of change: HIV/AIDS, patents and access to medicines for all. J. Int. AIDS Soc., vol. 14, no. 1, pp. 1-12.

[9] Medicine Patent Pool. 2012. WHO submission to the UN SG High Level Panel on access to medicines. Geneva: World Health Organization.

[10] UNITAID. 2010. UNITAID launches patent pool for HIV / AIDS drugs. Bridges, vol. 14, no. 21, pp. 2-3.

[11] Medicines Patent Pool. 2012. The medicines patent pool - Stimulating Innovation, Improving Access. Geneva: World Health Organization.

[12] Taylor, R.B. et al., 2011. The UNITAID patent pool initiative: Bringing patents together for the common good, Open AIDS J., vol. 2, no. 2, pp. 214-219.

[13] World Health Organization (WHO). 2002. Safety of medicines, Br. Med. J., vol. 4, no. 5834, p. 192

[14] Angamo, M.T., Chalmers, L., Curtain, C.M. and Bereznicki, L.R.E. 2016. Adverse-drug-reaction-related hospitalisations in developed and developing countries: A review of prevalence and contributing factors, Drug Saf., vol. 39, no. 9, pp. 847-857. 
[15] Mouton, J.P. et al., 2016. Adverse drug reactions causing admission to medical wards: A cross-sectional survey at 4 hospitals in South Africa, Med. (United States), vol. 95, no. 19, pp. 1-10.

[16] Masenyetse, L.J., Manda, S.O.M. and Mwambi, H.G. 2015. An assessment of adverse drug reactions among HIV positive patients receiving antiretroviral treatment in South Africa, AIDS Res. Ther., vol. 12, no. 1, pp. 1-8.

[17] Syed, I.A., Sulaiman, S.A.S., Hassali, M.A. and Lee, C.K.C. 2014. Adverse drug reactions and quality of life in HIV/AIDS patients: Advocacy on valuation and role of pharmacovigilance in developing countries, HIV AIDS Rev., vol. 14, no. 1, pp. 28-30.

[18] Tetteh, R.A. et al., 2016. Association between the occurrence of adverse drug events and modification of first-line highly active antiretroviral therapy in Ghanaian HIV patients, Drug Saf., vol. 39, no. 11, pp. 11391149.

[19] Manickum, V.K. and Suleman, F. 2012. Evaluating adverse drug reactions among HAART patients in a resource constrained province of South Africa, African J. AIDS Res., vol. 11, no. 2, pp. 75-81.

[20] Impicciatore, P., Choonara, I., Clarkson, A., Provasi, D., Pandolfini, C. and Bonati, M. 2001. Incidence of adverse drug reactions in paediatric in/out-patients: A systematic review and meta-analysis of prospective studies., Br. J. Clin. Pharmacol., vol. 52, no. 1, pp. 77-83.

[21] Bezabhe, W.M., Chalmers, L., Bereznicki, L.R., Peterson, G.M., Bimirew, M.A. and Kassie, D.M. 2014. Barriers and facilitators of adherence to antiretroviral drug therapy and retention in care among adult HIVpositive patients: A qualitative study from Ethiopia, PLoS One, vol. 9, no. 5.

[22] Oguntibeju, 0.0. 2012. Quality of life of people living with HIV and AIDS and antiretroviral therapy, HIVIAIDS - Research and Palliative Care, vol.4, pp. 117-124.

[23] Maponga, C.C., Ma, Q., Slish, J.C. and Morse, G.D. 2007. HIV pharmacotherapy issues, challenges , and priorities in sub-Saharan African countries, Top HIV Med., vol.15, no. 3, pp 104 -110.

[24] Haberer, J.E. et al., 2017. Review article: Improving antiretroviral therapy adherence in resource-limited settings at scale: A discussion of interventions and recommendations, Journal of the International AIDS Society, vol. 20, pp. 1-15.

[25] Houston, S. 2002. Justice and HIV care in Africa - Antiretrovirals in perspective, JIAPAC, vol. 1, no. 2, pp. 46-50.

[26] Stevens, W., Gous, N., Ford, N. and Scott, L.E. 2014. Feasibility of HIV point-of-care tests for resourcelimited settings: Challenges and solutions, BMC Med., vol. 12, no. 173, pp. 1-8.

[27] Djobet, M.P.N., Singhe, D., Lohoue, J., Kuaban, C., Ngogang, J. and Tambo, E. 2017. Antiretroviral therapy supply chain quality control and assurance in improving people living with HIV therapeutic outcomes in Cameroon, AIDS Res. Ther., vol. 14, no.19 pp. 1-8.

[28] Miller, V., Nwokike, J. and Stergachis, A. 2012. Pharmacovigilance and global HIV / AIDS, Curr. Opin. HIV AIDS, vol. 7, no. 4, pp. 299-304.

[29] Ampadu, H.H. et al., 2016. Adverse drug reaction reporting in Africa and a comparison of individual case safety report characteristics between Africa and the rest of the world: Analyses of spontaneous reports in VigiBase ${ }^{\circledR}$, Drug Saf., vol. 39, no. 4, pp. 335-345.

[30] Tassie, J., Bertagnolio, S. and Souteyrand, Y. 2011. Integrated surveillance of HIV care in low-income and middle-income countries, Curr. Opin. HIV AIDS, vol. 6, pp. 233-238.

[31] Olsson, S., Pal, S.N., Stergachis, A. and Couper, M. 2010. Pharmacovigilance activities in 55 low- and middle-income countries, Drug Saf, vol. 33, no. 8, pp. 689-703.

[32] World Health Organization. 2006. Medical records manual: A guide for developing countries. Geneva: World Health Organization.

[33] Rachlis, B. et al., 2016. Targeted spontaneous reporting: Assessing opportunities to conduct routine pharmacovigilance for antiretroviral treatment on an international scale, Drug Saf., vol. 39, no. 10, pp. 959-976.

[34] Fokam, J. et al., 2013. Declining trends in early warning indicators for HIV drug resistance in Cameroon from 2008 - 2010: Lessons and challenges for low-resource settings, BMC Public Health, vol.13, no. 308, pp. 1-10.

[35] World Health Organization. 2017. Executive Summary: WHO Global Surveillance And monitoring system for Substandard and Falsified Medical Products. Switzerland: World Health Organization.

[36] Johnston, A. and Holt, D.W. 2013. Substandard drugs: A potential crisis for public health. Br. J Clin. Pharmacol, vol. 78, no. 2, pp. 218-243.

[37] Nsimba, S.E.D. 2009. Anti-retroviral (ARV) rationing schemes in developing countries: a review article on strategies and ethical issues related to the successes and failures of ARVprogrammes, East African journal of public health, vol. 6, no. 2, pp. 220-225.

[38] Siva, N. Tackling the booming trade in counterfeit drugs, Lancet, vol. 376, no. 9754, pp. 1725-1726.

[39] 12[Accessed: 25-Apr-2018].

[40] Nilseng, J., Gustafsson, L.L., Nungu, A., Bastholm-rahmner, P., Mazali, D. and Pehrson, B. 2014. A cross-sectional pilot study assessing needs and attitudes to implementation of Information and Communication Technology for rational use of medicines among healthcare staff in rural Tanzania, BMC Medical Informatics and Decision Making, vol.14, no. 78, pp. 1-12.

[41] Steyn, F. et al., 2009. Scaling up access to antiretroviral drugs in a middle-income country: Public sector drug delivery in the Free State, South Africa, AIDS Care, vol. 21, no.1, pp. 1-6.

[42] Ford, N., Calmy, A. and Mills, E.J. 2011. The first decade of antiretroviral therapy in Africa, Globalization and Health, vol. 7, no. 33, pp. 1-6. 
[43] Lahuerta, M.M., Ue, F., Hoffman, S., Elul, B., Kulkarni, S.G., Wu, Y., Nuwagaba-Biribonwoha, H., Remien, R.H., El Sadr, W. and Nash, D. 2013. The problem of late ART initiation in sub-Saharan Africa: A transient aspect of scale-up or a long-term phenomenon?, J. Heal. Care Poor Underserved, vol. 24, no.1, pp. 359-383.

[44] Muhamadi, L. et al., 2010. Inadequate pre-antiretroviral care, stock-out of antiretroviral drugs and stigma: Policy challenges / bottlenecks to the new WHO recommendations for earlier initiation of antiretroviral therapy ( $C D<350$ cells / $\square$ L ) in Eastern Uganda, Health Policy, vol. 97, no. 2-3, pp. 187-194.

[45] Phelps, B.R. and Rakhmanina, N. 2011. Antiretroviral drugs in paediatric HIV-infected patients: Pharmacokinetic and practical challenges, Pediatr. Drugs., vol. 13, no. 3, pp. 175-192.

[46] Keiser, J. and Utzinger, J. 2010. The drugs we have and the drugs we need against major helminth infections, Adv. Parasitol., vol. 73, pp. 197-230.

[47] Bertagnolio, S., Perno, C.F., Vella, S. and Pillay, D. 2013. The impact of HIV drug resistance on the selection of first- and second-line ART in resource-limited settings, Journal of Infectious Diseases, vol. 207, no.SUPPL 2, pp. 45-48.

[48] Wallis, C.L., Godfrey, C., Fitzgibbon, J.E. and Mellors, J.W. 2018. Key factors influencing the emergence of human immunodeficiency virus drug resistance in low- and middle-income countries, Journal of Infectious Diseases, vol. 216, no.SUPPL 9, pp. 851-856.

[49] World Health Organization. 2016. Meeting report: Technical definitions of shortages and stockouts of medicines and vaccines, Geneva: World Health Organization.

[50] Pasquet, A. et al., 2010. Impact of drug stock-outs on death and retention to care among HIV-infected patients on combination antiretroviral therapy in Abidjan, Côte d'Ivoire, PLoS One, vol. 5, no. 10, pp. 19.

[51] Stop Stock Outs Projects. 2016. Stop Stockouts: SSP Stockouts National Survey. South Africa.

[52] Dubrocq, G., Rakhmanina, N. and Phelps, B.R. 2017. Challenges and opportunities in the development of HIV medications in paediatric patients, Pediatr. Drugs., vol. 19, no. 2, pp. 91-98.

[53] Dahinten, A.P., Dow, D.E., Cunningham, C.K. and Msuya, L.J., Mmbaga, B.T. and Malkin, R.A. 2016. Providing safe and effective preventative antiretroviral prophylaxis to HIV-exposed newborns via a novel drug delivery system in Tanzania, Pediatr. Infect. Dis. J., vol. 35, no. 9, pp. 987-991.

[54] Kisangau, D.P., Lyaruu, H.V.M., Hosea, K.M. and Joseph, C.C. 2007. Use of traditional medicines in the management of HIV/AIDS opportunistic infections in Tanzania: A case in the Bukoba rural district, J. Ethnobiol. Ethnomed., vol. 3, no. 29, pp. 1-8.

[55] Kloos, S. 2017. Rethinking Sowa Rigpa and the Herbal Pharmaceutical Industry in Asia, Current Anthropology, vol. 58, no. 6, pp. 693-717.

[56] Perampaladas, K., Masum, H., Kapoor, A., Shah, R., Daar, A.S. and Singer, P.A. 2010. The road to commercialization in Africa: Lessons from developing the sickle-cell drug Niprisan, BMC Int. Health Hum. Rights, vol. 10, no. SUPPL. 1, pp. 1-7.

[57] Sahoo, N. and Manchikanti, P. 2013. Herbal drug regulation and commercialization : An Indian industry perspective, The Journal of Alternative and Complementary Medicine, vol. 19, no. 12, pp. 957-963.

[58] Wechsler, J. 2016. Drug shortages raise economic and ethical challenges, Pharmaceutical Executive, vol. 36, no. 8.

[59] Jaskot, D. et al., 2011. Globalizing the FDA: Achieving safety, access, and transparency through a comprehensive Generic Drug User Fee Program, Journal of Generic Medicines, vol. 8, no. 4, pp. 198 - 203.

[60] Busza, J. et al., 2018. The role of community health workers in improving HIV treatment outcomes in children: Lessons learned from the ZENITH trial in Zimbabwe, Health Policy and Planning, vol. 33, no. 3, pp. 328-334.

[61] World Health Organization. 2007. Survey of the quality of antiretroviral medicines circulation in selected African countries. Geneva: World Health Organization

[62] Kankhar, S. 2006. IT-based drug discovery: Future driver for the Australian Pharmaceutical IT Market, [Online]. Available: http://www.frost.com/prod/servlet/market-insight-print.pag?docid=68419421. [Accessed: 28-May-2018].

[63] Strengthing Pharmaceutical Systems SPS. 2009. Indicator-based pharmacovigilance assessment tool: Manual for conducting assessments in developing countries. Arlington: Management Sciences for Health. 